\title{
ENDOGENOUS GROWTH AND STOCHASTIC TRENDS
}

\author{
Antonio FAtás* \\ INSEAD, 77305 Fontainebleau, France
}

\begin{abstract}
This paper shows that in a cross section of countries there exists a strong positive correlation between long-term growth rates and the persistence of output fluctuations. We argue that the traditional explanation of persistence, an RBC model with exogenous productivity shocks, cannot account for this correlation. What is required is a model where the stochastic nature of the trend is endogenous and growth dynamics is an important component of the transmission of business cycles. We present a stylized endogenous growth model with exogenous cyclical shocks where, despite the cyclical nature of the shocks, output fluctuations are persistent and the degree of persistence is an increasing function of long-term growth rates.
\end{abstract}

Keywords: Business Cycles, Persistence, Growth, Stochastic Trends.

JEL Classification: C22, E32, O40.

Correspondence to: Antonio Fatás, INSEAD, Boulevard de Constance, 77305 Fontainebleau, France. E-mail: fatas@insead.fr. Phone: 331607244 19. Fax: 33160724242

* I wish to thank an anonymous referee, the Editor and seminar participants at ECARE, INSEAD, the Graduate Institute of International Studies and Univ. Paris I for helpful comments on previous drafts of the paper. 


\section{INTRODUCTION}

A common question in the literature on economic fluctuations is whether all business cycles are alike. Differences in business cycles across countries provide a good benchmark to test the predictions of alternative theories of the cause and transmission of economic fluctuations.

An important stylized fact of business cycles is the persistence of output fluctuations. By persistent fluctuations we mean output fluctuations that are long lasting. More precisely, a shock to GNP is persistent when its effects do not dissipate in the near future and GNP does not show a significant tendency to return to its trend level. After the work of Nelson and Plosser (1982), the prevailing view on persistence is that the effects of a shock last forever and, thus, GNP has a unit root. As a result, after a decline in GNP today, forecasts of GNP are lowered over any possible horizon. These results have been widely confirmed using data from different countries. For example, Campbell and Mankiw (1989) show that quarterly GNP, for the group of G-7 countries, is highly persistent. For all these countries, a $1 \%$ decline in output today, lowers the long-run forecast of output by even more than $1 \%$. Their estimates of persistence display, however, large differences across countries. All countries, with the exception of the United Kingdom, exhibit fluctuations that last longer than in the US. For example, persistence in Japan is between 2 and 5 times larger than in the US. These results are further confirmed by Cogley (1989) who shows, for a similar sample of countries, considerable differences in the variability of the permanent component of output.

This paper analyzes cross-country differences in persistence and provides an explanation which has interesting implications for the interactions between growth and business cycles. We argue that an explanation to the observed differences in persistence requires a model where fluctuations are not just deviations around a trend determined by technological progress. A distinctive element of the explanation must be that the stochastic properties of the trend are not exogenous (as in the standard real business cycle model) but that they are the result of the endogenous response of technology to business cycles.

\section{[Insert Figure 1 here]}

Figure 1 plots the degree of persistence (as measured by Cochrane's variance ratio with a window of 20 quarters) of quarterly GNP against its long-term (38 years) average growth rate for the G-7 countries. There is an almost perfect correlation between both variables. The standard explanation of persistence, an 
RBC model where fluctuations are driven by exogenous permanent productivity shocks, predicts no correlation between them. ${ }^{1}$ More precisely, if in all these countries GNP followed a random walk with a drift we would expect all data points in Figure 1 to be lying on a horizontal line around $V=1$. In fact, the $\mathrm{X}$-axis variable of Figure 1 is generally absent in business cycle models. It represents the long-run trend of output which is commonly captured by a technological progress drift that is treated as exogenous. The positive correlation of Figure 1 indicates that analyzing significant features of the business cycle, such as persistence, in models where growth is treated as exogenous can be misleading.

In this paper we show that the positive correlation of Figure 1 is a natural outcome of a model where growth is endogenous and responds to business cycle fluctuations. The intuition is simple, as long as the amount of resources allocated to growth is procyclical, we expect transitory changes in the growth rate of trend GNP to produce long-lasting (permanent) effects in the level of output. Under this view, persistence represents a measure of the effects that fluctuations have on technological progress, which establishes a link between long-term growth and short-term persistence. Furthermore, as long as growth reacts proportionally to cyclical shocks, a fast-growing economy will have a larger degree of short-run persistence than a slow-growing one. ${ }^{2}$ This is true even if the stochastic properties of the underlying shocks are the same for both economies. In other words, similar shocks have larger permanent effects in a fast-growing economy.

Our explanation, by making explicit the interactions of economic fluctuations and growth, sheds light on the interpretation of the decompositions of output into a permanent and a transitory component. Under the traditional assumption that persistence originates in exogenous permanent productivity shocks, these decompositions have been extensively used to distinguish between supply (permanent) and demand (transitory) shocks. However, when persistence is interpreted as a measure of the permanent effects that fluctuations have on growth, then the degree of persistence of a shock does not contain any information about its origin. This result, previously explored in King, Plosser and Rebelo (1988) and Stadler (1989 and 1990), implies that, as long as technological progress is procyclical, temporary shocks (productivity, taste or aggregate demand shocks) can generate persistent fluctuations.

The type of model we propose also has more general implications about the

\footnotetext{
1 Unless one is willing to assume that a larger growth rate implies more persistent disturbances to the production function.

2 The notion of proportionality will be precisely defined later in the paper.
} 
measurement and identification of business cycles. The trend and cycle components of output are correlated with each other and fluctuations cannot be simply measured as deviations from a steady state. At the same time, this interaction between economic fluctuations and growth can possibly lead to larger measures of the welfare costs of business cycles.

The paper is organized as follows. Section 2 reviews the previous literature on stochastic trends. Section 3 looks at additional evidence on the correlation shown in Figure 1 using different frequencies and a larger sample of countries. Section 4 develops a stylized endogenous growth model with exogenous cyclical fluctuations that is able to produce a positive correlation between persistence and growth. Section 5 discusses alternative interpretations of our results and Section 6 concludes.

\section{STOCHASTIC TRENDS}

The work of Nelson and Plosser (1982) challenged the traditional method of measuring business cycles as temporary deviations of output from a deterministic trend. Although there is still an open debate about the existence of an exact unit root in output, there is a broad agreement that fluctuations are highly persistent; GNP shows practically no tendency to revert to its trend level after a disturbance. As a result, the concept of a deterministic trend has been generally abandoned in favor of the notion of a stochastic trend and, as an example, filtering out cyclical components by using log differences, which presumes the existence of an stochastic trend, is standard practice today.

What are the implications of the presence of a stochastic trend in GNP for economic modeling? The presence of a stochastic trend is linked to the notion of stochastic growth. Models that fall into this label can be grouped into two different categories. First, there are models where the source of dynamics (exogenous permanent productivity shock) is the sole responsible of the existence of a stochastic trend. Second, there are models where the stochastic nature of growth is the result of the effects that fluctuations have on growth. Both of these types of models have quite similar empirical predictions but their assumptions about the cause of output fluctuations and their welfare implications can be fundamentally different. We next review the basic assumptions behind each of these types of models.

\section{Exogenous Permanent Productivity Shocks}

The initial explanation to the persistence of GNP fluctuations was provided 
by the real business cycle literature. In the standard RBC model, fluctuations are deviations from a steady-state solution to a neoclassical growth model. In its simplest form, GNP per capita follows a random walk with a drift, where the drift is exogenously determined by the rate of labor-augmenting technological progress. Furthermore, only small deviations around a steady state are analyzed and transitional growth dynamics are practically ignored. In this setup, permanent exogenous shifts in the production function are the only possible source of the persistence of output fluctuations. ${ }^{3}$

This model was the benchmark to interpret empirical decompositions of GNP into a permanent and a transitory component. These decompositions identify low-frequency output variability with exogenous technology shocks, while highfrequency movements are considered as demand shocks. As a result, the empirical contribution of the permanent component of output is regarded as a measure of the size and frequency of technology shocks relative to demand shocks. ${ }^{4}$ All these papers confirm the significant contribution of the permanent component of GNP but they pay very little attention to the observed cross-country differences. For example, Cogley (1990) studies the variability of the low-frequency component of output in a sample of 9 countries and shows that there are significant differences among them, the US having the most stable low-frequency component of the sample. He concludes that output fluctuations, at least within his sample, are not all alike. If we were to use the standard RBC model as a benchmark to explain these cross-country differences, we would need to assume differences in the underlying stochastic process that drives technology shocks. The correlation of Figure 1 suggests, however, that average growth rates contain valuable information about the observed differences in the behavior of the long-term component of output. For this reason, we propose to incorporate in the analysis the endogeneity of productivity growth in order to understand its possible interactions with the persistence of economic fluctuations.

\section{Endogenous Growth and Stochastic Trends}

When productivity growth or technological progress are the outcome of conscious decisions made by economic agents, the notion of persistent fluctuations might have a very different interpretation. King, Plosser and Rebelo (1988) and Stadler (1989) noticed that, within the context of an endogenous growth model, there are many types of disturbances, different from permanent shifts in the pro-

\footnotetext{
3 See, for example, Kydland and Prescott (1982) or King, Plosser, Stock and Watson (1991).

4 See Blanchard and Quah (1989), Campbell and Mankiw (1987), King, Plosser, Stock and Watson (1991) or Shapiro and Watson (1988)
} 
duction function, that can produce persistent fluctuations. More specifically, any temporary disturbance causes permanent effects on the level of output as long as it produces temporary changes in the amount of resources allocated to growth. The growth mechanism adds up the transitory deviations to lead to a unit-root series of output. In this case, persistence cannot be used anymore to identify shocks and, as a consequence, the emphasis of the analysis shifts from the origin to the transmission of the shocks. A corollary is that disturbances such as aggregate demand shocks, traditionally considered as temporary, can have permanent effects on the level of economic activity.

Endogenous vs. Exogenous Stochastic Trends

The two sets of models described above share the presence of an stochastic trend and, as a result, they are able to produce persistent output fluctuations. However, the stochastic properties of the trend are exogenously assumed in the first case while they are the result of the response of productivity to cyclical fluctuations in the second one. Furthermore, their implications in terms of the cause and welfare costs of economic fluctuations can be quite different. It is nevertheless difficult to design tests to empirically distinguish between both explanations as their predictions are, in most cases, almost identical. In this paper, we propose to use the correlation of Figure 1 as a test for both explanations. Next section presents additional evidence of the positive correlation between persistence and growth.

\section{EMPIRICAL EVIDENCE}

In this section we study the robustness of the correlation of Figure 1 by looking at different frequencies and a larger sample of countries. We first discuss the measurement of persistence.

\subsection{Measuring Persistence}

Let $y_{t}$ be the log of output and assume that it has the following Wold representation

$$
\Delta y_{t}=D(L) \epsilon_{t}
$$

Where $D(L)=d_{0}+d_{1} L+d_{2} L^{2}+d_{3} L^{3}+\ldots$ is a lag polynomial. Then, the coefficients $d_{j}$ measure the impact of a shock $\epsilon_{t}$ on the growth rate of GNP in period $t+j$. If we add up these coefficients we can find the impact of a given shock on the level of GNP. In general,

$$
P^{J}=\sum_{j=0}^{j=J} d_{j}
$$


represents the impact of a shock $\epsilon_{t}$ on the level of output at $t+J$. The infinite sum of all $d_{j}$ coefficients, measures the permanent impact of a given shock on the level of output, let $P$ be this sum,

$$
P=\lim _{J \rightarrow \infty} P^{J}=D(1)
$$

A second measure of persistence proposed by Cochrane (1988), is a ratio of variances that can also be written as a weighted sum of autocorrelations

$$
V^{J}=\frac{(1 / J) \operatorname{var}\left(y_{t}-y_{t-J}\right)}{\operatorname{var}\left(y_{t}-y_{t-1}\right)}=1+2 \sum_{j=1}^{J-1}(1-j / J) \rho_{j}
$$

where $\rho_{j}$ is the $j$-th autocorrelation of the growth rate of output. Taking the limit of this expression as $J$ tends to infinity, we obtain a measure of long-run persistence,

$$
V=\lim _{J \rightarrow \infty} V^{J}
$$

Both $V$ and $P$ take value 0 for a trend-stationary series and value 1 for a random walk. For any other series,

$$
V=|P|^{2} \frac{\operatorname{var}(\epsilon)}{\operatorname{var}(\Delta y)}
$$

\subsection{Cross-Country Evidence}

Figure 1 showed a positive and significant correlation between the degree of persistence of short-term fluctuations and long-term average growth rates for the group of G-7 countries. Figure 2 enlarges the sample including eight additional OECD countries for which quarterly data on production is available. ${ }^{5}$ Table 1 shows the regression results. The fit is still very good (the explained variance is $75 \%)$ and the coefficient is positive and significant. The size of the coefficient is indeed very similar in both samples.

\section{[Insert Figure 2 here]}

Figure 3 uses annual data from the Summers-Heston data set for the same group of countries. The result is confirmed and both the fit and the significance of the parameter are similar to the ones found above. For the group of G-7 countries, one even finds a stronger relation. Table 2 shows these results.

\footnotetext{
5 Production is measured as GNP or GDP, when available, or Industrial Production.
} 
Table 1. Regression Results. Quarterly Data

\begin{tabular}{lccc}
\multicolumn{3}{c}{ Persistence $_{i}=\beta_{0}+\beta_{1}$ Avg. Growth } \\
Sample & $\beta_{0}$ & $\beta_{1}$ & $R^{2}$ \\
\hline G-7 & -1.55 & 4.12 & 0.95 \\
& $(0.41)$ & $(0.43)$ & \\
Full (15 countries) & -1.05 & 3.38 & 0.75 \\
& $(0.47)$ & $(0.54)$ & \\
\hline
\end{tabular}

Sample: 1950-1994

Standard errors in parentheses.

Table 2. Regression Results. Annual Data

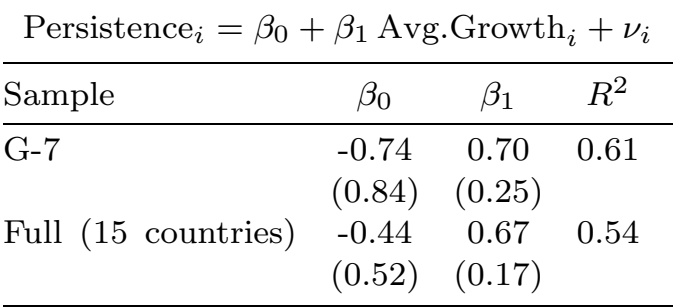

Sample: 1955-1991

Standard errors in parentheses.

\section{[Insert Figure 3 here]}

We have also performed the regressions of Tables 1 and 2 using different measures of persistence. We estimated univariate autoregressive processes for output growth and computed the parametric measure of persistence $P$, as defined in Section 3.2. The results were confirmed in all cases, the coefficient was always positive and significant and the fit of the regression was similar to the ones above. ${ }^{6}$

\section{A THEORETICAL EXPLANATION}

The empirical results of the previous section suggest that the long-term growth rate of output contains valuable information to explain cross-country differences in business cycle persistence. In this section, we present a simple stylized model that is able to generate a positive correlation between these two variables. Growth is the outcome of investment in physical capital and we add uncertainty to the model by assuming transitory productivity shocks. We adopt this model for its simplicity and similarity to RBC models used to analyze business cycles. Section 5 discusses

6 For example, computing $P$ from fitting an AR(2) process to GNP per capita growth, the 15 countries sample results in an $R^{2}$ of 0.69 and a slope of 0.37 (with a standard error of 0.07 ). In the G-7 sample the $R^{2}$ is 0.65 and the slope is 0.37 (with a standard error of 0.12 ). 
possible generalizations of the model and whether alternative explanations can account for our empirical results.

\subsection{Certainty: Steady-State Growth}

The production function is

$$
Y_{t}=A K_{t}
$$

where $Y$ represents output, $K$ is the aggregate capital stock and $A$ is a countryspecific parameter that will generate differences in long-term growth rates. ${ }^{7}$ The single representative consumer maximizes the utility function

$$
U=E_{0} \sum_{t=0}^{\infty} \beta^{t} \frac{C_{t}^{1-\gamma}}{1-\gamma}
$$

subject to the budget constraint

$$
K_{t+1}=K_{t}(1-\delta)+\left(Y_{t}-C_{t}\right)
$$

where $\delta$ is the depreciation rate.

The solution to this model is characterized by a constant saving rate and a balanced-growth path. Thus, we rewrite the maximization problem in terms of the saving rate, $S$, defined as the proportion of income that is not being consumed. Consumption can be written as $C_{t}=A K_{t}\left(1-S_{t}\right)$ and the budget constraint is just

$$
\frac{K_{t+1}}{K_{t}}=(1-\delta)+A S_{t}
$$

\section{Steady-state solution}

In the absence of uncertainty, maximizing the utility function (1) subject to the constraint (4) leads to a balanced-growth path solution with a constant saving rate where $Y, C$ and $K$ all grow at the same rate. The equilibrium value for the saving rate and the growth rate are

$$
\begin{gathered}
S^{*}=\frac{\beta(A+(1-\delta))^{\frac{1}{\gamma}}-(1-\delta)}{A} \\
G^{*}=\frac{1}{\gamma} \ln [\beta(A+(1-\delta))]
\end{gathered}
$$

7 To concentrate on productivity growth dynamics we have assumed that labor is supplied inelastically and normalize the labor supply to 1 . 
We will refer to these values as steady-state values.

Cross-country differences in growth rates

We assume that countries differ in the parameter $A$ and that this is the source of differences in steady-state growth rates. All other parameters in the model are assumed to be equal for all countries. From (6), the steady-state growth rate $\left(G^{*}\right)$ is an increasing function of $A$. Therefore, our assumption implies that fast-growing economies are characterized by a larger $A$. This identification of the source of long-term growth differences will be important when we look at how persistence depends on $G^{*}$.

\subsection{UnCERTAINTY: CYCLICAL SHOCKS}

We now introduce uncertainty to the model by assuming transitory exogenous shocks and analyze the dynamic behavior of output around the steady state. We introduce an additional variable in the production function that captures the state of technology, $Z_{t}$. The production function is now

$$
Y_{t}=Z_{t} A K_{t}
$$

Uncertainty originates in $Z_{t}$ which is assumed to follow an stochastic process with the Wold representation

$$
\hat{z}_{t}=C(L) \epsilon_{t}
$$

where small letters represent logarithms and a circumflex on top of the variable denotes deviations from its steady-state value. For simplicity we will assume that the steady-state value of $Z_{t}$ is $1 . C(L)$ is a lag polynomial, $C(L)=1+c_{1} L+$ $c_{2} L^{2}+c_{3} L^{3}+\ldots$ where all roots are assumed to be less than one so that the stochastic process is stationary. The stationarity of $\hat{z}$ allows us to refer to this process as cyclical. We need to emphasize that our results are not dependent on the specific origin of the shock (in this case technology). We look, for simplicity, at temporary technology shocks but other types of cyclical shocks (e.g. aggregate demand shocks) would lead to similar output responses. ${ }^{8}$

Maximization of the expected utility function (2) leads to the following firstorder condition

$$
\left[\frac{(1-\delta)+A S_{t} Z_{t}}{A Z_{t}\left(1-S_{t}\right)}\right]^{\gamma}=\beta E_{t}\left[\frac{A Z_{t+1}+(1-\delta)}{\left[A Z_{t+1}\left(1-S_{t+1}\right)\right]^{\gamma}}\right]
$$

8 For example, Stadler (1989) and Fatás (1994) present endogenous growth models with aggregate demand shocks resulting in persistent fluctuations. 
Equations (4) and (8) define the equilibrium dynamics of the model. As a general closed-form solution to the equilibrium does not exist, our strategy is to approximate the equilibrium solution by linearizing both equations around the steady-state values $\left(S^{*}\right.$ and $\left.G^{*}\right)$. From the linearization of the first order condition we obtain an expression like

$$
\kappa_{1} \hat{S}_{t}+\kappa_{2} \hat{z}_{t}=\kappa_{3} E_{t}\left(\hat{S}_{t+1}\right)+\kappa_{4} E_{t}\left(\hat{z}_{t+1}\right)
$$

Where all $\kappa_{i}$ 's are functions of the parameters of the model. ${ }^{9}$ This is a linear first-order stochastic difference equation. We assume, for simplicity, that $\hat{z}_{t}$ follows an $\operatorname{AR}(1)$ process

$$
\hat{z}_{t}=\rho \hat{z}_{t-1}+\epsilon_{t}
$$

Using this assumption, (9) can be rewritten as

$$
\kappa_{1} \hat{S}_{t}=\kappa_{3} E_{t}\left(\hat{S}_{t+1}\right)+\left(\rho \kappa_{4}-\kappa_{2}\right) \hat{z}_{t}
$$

and the solution takes the form

$$
\hat{S}_{t}=\kappa \hat{z}_{t}
$$

where

$$
\kappa=\frac{\rho \kappa_{4}-\kappa_{2}}{\kappa_{1}-\rho \kappa_{3}}
$$

We can now plug this expression into the budget constraint to obtain the equilibrium value for the growth rate. We linearize the resulting expression around the steady state to obtain a solution for the growth rate of capital which is linear in the productivity parameter. Let $\theta$ be the coefficient on that linearization so that $^{10}$

$$
\widehat{\Delta k_{t}}=\theta \hat{z}_{t}
$$

where

$$
\theta=\frac{\kappa A+A S^{*}}{(1-\delta)+A S^{*}}
$$

Using the production function (1) together with (10) and (12), we obtain an expression for the deviations of output growth from its steady state value $\left(G^{*}\right)$

$$
\widehat{\Delta y_{t}}=(1-L) \hat{z}_{t}+\theta L \hat{z}_{t}=(1-(1-\theta) L) C(L) \epsilon_{t}
$$

\footnotetext{
9 See the appendix for the mapping between these parameters and the deep parameters of the model.

10 Where capital growth is measured as deviations from its steady state value $G^{*}$.
} 
We can now use (13) to evaluate the stochastic properties of output.

\subsection{Persistence And Growth}

We now turn to the measures of persistence defined in Section 3.1 and apply them to the model by using (13). One should note that, although the type of disturbances that we are considering are cyclical, the model generates a unit-root series of output, both $V$ and $P$ are greater than zero. The reason for having a non-stationary output series is that shocks have an effect on capital accumulation. After the cyclical effects vanish, output does not return to its trend level and, thus, the shock has permanent effects. One can verify this property in equation (13) by showing that, as long as $\theta \neq 0$, output has a unit root.

The second issue of interest is how the measures of persistence vary with the parameter $\theta$, which represents the contemporaneous impact that shocks have on capital accumulation. $P$ and $V$ can be written as

$$
\begin{gathered}
P=\frac{\theta}{1-\rho} \\
V=\frac{\theta^{2}\left(1-\rho^{2}\right)}{(1-\rho)^{2}\left(\theta^{2}+2(1-\rho)(1-\theta)\right)}
\end{gathered}
$$

which are both increasing in $\theta .^{11}$

Once we have established a connection between persistence and the parameter $\theta$, now we want to use our previous assumption about cross-country differences in the technological parameter $A$, to obtain an expression that relates persistence and $G^{*}$. For simplicity, we restrict our attention to the case of a logarithmic utility function $(\gamma=1)$. In this case, $\theta$ takes the value

$$
\theta=\frac{A}{A+(1-\delta)}
$$

which is increasing in $A$ (as long as the depreciation rate, $\delta$, is less than one). Therefore, countries with a higher $A$ will have both a higher steady-state growth rate and a higher $\theta$. This, together with the fact that persistence is increasing in $\theta$, predicts a positive correlation between persistence and long-term growth rates, the result of Figure $1 .{ }^{12}$

\footnotetext{
11 See the appendix for the calculations that lead to these two expressions.

12 When $\gamma \neq 1$, the solution for $\theta$ turns out to be much more complex and analytically intractable. We have numerically explored the solution by calibrating the model to fit differences in growth rates.
} 
We can summarize all the previous arguments by making explicit the relation between persistence and the steady-state growth rate of output $\left(G^{*}\right)$. To do so, we calculate the required value for $A$ in equation (5) and plug it in the expression for $P$ to obtain

$$
P=\left[1-\frac{(1-\delta) \beta}{\exp \left(G^{*}\right)}\right] \frac{1}{1-\rho}
$$

which shows that persistence is increasing in the steady-state growth rate $\left(G^{*}\right)$.

As a summary, we have found that the larger the growth rate is, the larger the absolute response of capital accumulation to a shock is $(\theta)$. This leads to a positive correlation between persistence and growth which mimics the result of Figure 1.

To understand the economic intuition behind this result let's look at an extreme case. Let's compare two economies, one of which has no growth and no investment (assume, for simplicity, zero depreciation of capital). The logic of our model is that the response of output to cyclical shocks becomes persistent because of the growth that is lost during a recession due to a transitory decrease in the amount of resources allocated to capital accumulation. ${ }^{13}$ But in the case of the stagnant economy, with no growth, this effect will not be present and, as a result, persistence will simply be equal to the persistence of the cyclical shocks. Indeed, in the long run, persistence will be zero. If we compare this with the growing economy where shocks leave permanent effects on output, we will observe that the higher the growth rate, the higher the persistence. What about the general case, when we compare two countries with positive growth rates? Assume that trend output is growing at a $6 \%$ rate in country $X$, and at a smaller rate, say $2 \%$, in country $Y$. Suppose they both suffer a common temporary shock of equal magnitude. The fact that $\theta$ is larger in country $X$ implies that the absolute response of its long-term growth rate is going to be larger than in country $Y$. For example, while in country $Y$ the rate might drop, as a consequence of the shock, to $1 \%$ (a drop of one percentage point), in $X$ the rate drops to, say, 3\% (a drop of three percentage points). ${ }^{14}$ These numbers imply that the permanent effects of the shock on the level of output will be larger in country $X$ than in country $Y$, exactly what the measures of persistence would say.

We found that, for a plausible range of values of $\gamma, \theta$ is always positively related to the steady-state growth rate. The same result is obtained when we assume that differences in long-term growth rates are originated in differences in $\gamma$ and not in $A$.

13 The argument is symmetric and applies equally to positive shocks.

14 In this example, the response of the growth rate of the trend is proportional; in both cases the rate drops by one third. This is, of course, not necessary. What is needed is that the absolute fall in the rate is larger in the country with a higher steady-state growth rate. 
Dynamic Response of Output

The previous result can also be represented by drawing the impulse response function for different steady-state growth rates. We have calibrated our model to represent two economies with different steady-state growth rates of $2 \%$ and $6 \%$. Figure 4 shows the response of output to a transitory productivity shock for both cases. $^{15}$

\section{[Insert Figure 4 here]}

\section{[Insert Figure 5 here]}

In the case where $G^{*}=6 \%$, the response of output is more persistent and the permanent effects are larger than in the $2 \%$ case. Figure 5 decomposes the response of output into a cyclical component (the cyclical productivity shock) and a trend component (the capital stock). It shows that the difference in the response of output of Figure 5 is entirely caused by differences in the response of the permanent component. The cyclical shock is identical in both cases, but the response of the permanent component is more pronounced for $G^{*}=6 \%$ than for $G^{*}=2 \%$.

\section{DISCUSSION}

The model of Section 4 presents an explanation of the positive correlation between growth and persistence. In this section we discuss several implications of this interpretation and whether other models are able to replicate our empirical findings.

\subsection{Is Endogenous Growth Necessary?}

To what extent is endogenous growth necessary to generate a positive correlation between persistence and growth? Can an exogenous growth model (Solow type) generate the same results? Let's take as a benchmark the basic RBC model with exogenous technological progress and where business cycles are deviations around the steady state, defined by a Solow-type growth model. ${ }^{16}$ In this case, technological progress is represented as a drift and, to be able to generate a positive correlation between growth and persistence, one would need to add the

\footnotetext{
15 We calculate these responses by setting $\beta=0.96, \delta=0.07, \rho=0.5$ and $\gamma=3$. Each of the steady-state growth rates is associated with a different value of the parameter $A$.

16 See, for example, Kydland and Prescott (1982) or King, Plosser, Stock and Watson (1991).
} 
ad-hoc assumption that the shocks to the production function are more persistent when the rate of technological progress is higher. ${ }^{17}$

An alternative would be to deviate from the standard practice of looking at business cycles as fluctuations around the steady state and model countries in different positions in their convergence to the steady state. In this case, and depending on the speed of convergence and the initial position of different countries, one could observe a correlation similar to the one presented in our empirical estimates. Of course, strictly speaking, in an exogenous growth model, a transitory shock cannot have a permanent impact on the level of GDP per capita as, in the long run, the country will reach the unchanged steady-state level of output. But, the shock might have very persistent effects on output as the mechanics of capital accumulation, which are responsible for convergence, react to the shock. Clearly, if the speed of convergence is very slow, the properties of the model will be very similar to the ones of an endogenous growth model and, in a small sample, both models might be very hard to distinguish empirically. ${ }^{18}$ The spirit of such model would be very similar to the one presented in Section 4, as the key ingredient would be that persistence is the result of the effects of transitory shocks on the growth dynamics of output.

\subsection{Is Endogenous Growth Sufficient? Scale Effects}

Do all endogenous growth model predict a positive correlation between persistence and growth? The answer is clearly no as there are several additional factors that need to be present in the model. The most important one is that the variables that are driving long-run growth must comove with business cycles. A model where fluctuations do not have an effect on the resources responsible for growth will generally predict no correlation between growth and persistence. In fact, there are models which argue that the effects of business cycles and growth is, in some sense, the opposite as the one postulated in this paper. These models argue that the opportunity cost of research and innovations is lower during recessions and if recessions have any permanent effect on output, is a positive one. ${ }^{19}$ Indeed, in this type of models, a negative shock will increase the long-run forecasts of output. This result is hard to reconcile with the existing evidence on persistence.

A related question is to what extent our results originate in the presence

17 This assumption probably has testable implications of cross-country differences in business cycles.

18 These empirical issues are equivalent to the ones present in the debate on whether some time series are characterized by an exact unit root.

19 See, for example, Hall (1991), Gali and Hammour (1991) and Caballero and Hammour (1994). 
of scale effects. The answer to this question depends on the definition of scale effects. As stated above, what is needed is that those variables that are responsible for growth react to business cycles. A model like the one of Section 4, where investment in physical capital drives steady-state growth, is subject to scale effects. A change in the parameter $A$ could be thought of as a change in the scale of the economy that will lead to higher growth, given that capital accumulation depends on this parameter. But this scale effect is not needed to generate our results. For example, one could think about a model where research expenditures drive technological progress and, as long as business cycles affect the profitability of research, our intuition would be preserved. Some of these models do not display scale effects in the sense that an increase in the size of the economy (e.g. the labor force) does not generate an increase in the steady-state growth rate. At the same time, these models are compatible with some of the empirical regularities used as a criticism against endogenous growth models with scale effects. For example, in Aghion and Howitt (1998), Chapter 2, a Schumpeterian model of growth is presented where the steady-state growth depends on several variables that could be responsive to output fluctuations. As long as the response of these variables is similar to the one described in the model of Section 3, there will be a positive correlation between growth and persistence. ${ }^{20}$

Jones (1995) has taken the issue of scale effects further and argue that to be in accordance with certain empirical regularities, the steady-state growth rate of output cannot depend on the investment rate or on the share of resources dedicated to R\&D. In Jones's model, the solely determinant of long-term growth is population growth. Can one reconcile this model with our empirical results? The answer is no. ${ }^{21}$ Even if business cycle shocks affect the investment rate or the share of population in research activities, they will not leave any permanent effect in the level of output because, in his model, any transitory change in the investment rate only has transitory effects on the level of output. Indeed, this model has, to a great extent, Solow-type properties when it comes to the effect of changes in the investment rate and the logic is similar to what we discussed in Section 5.1.

\subsection{Volatility, Persistence and Growth.}

When looking at the connection between business cycles and growth, there are

\footnotetext{
20 Discussing how some of these variables might react to business cycles is beyond the scope of this paper. In addition to the logic of the model in Section 4, one could also introduce additional reasons why these variables are procyclical such as liquidity constraints. For evidence on the procyclicality of R\&D expenditures see Fatás (1994).

21 Unless one can find a link between population growth and business cycles.
} 
several papers that stress the possibility that business cycle volatility is harmful for growth because of the negative effects on investment. ${ }^{22}$ Is there a relationship between this literature and our results? The answer is no. The correlation that we have presented in this paper is between growth and persistence. Persistence is measured as a ratio of variances and therefore has no direct connection with volatility. Our results suggest that the volatility of the permanent component of output is larger for countries with high growth rates, but it does not imply anything about the overall volatility of output. In fact, in our model, the causality runs from growth to persistence and, in this sense, we cannot say anything about whether volatility is good or bad for growth because the effects of cyclical shocks on output trend are symmetric. If we had different economies being subject to different cyclical shocks, the volatility of these shocks would have no effect on growth performance.

To illustrate this point, Figure 6 looks at the correlation between the average growth rate of output and its volatility (standard deviation of GNP growth rate) for the sample of countries in Figure 3. As it clear from the graph, there is no relationship in our data between growth and volatility. ${ }^{23}$

\section{[Insert Figure 6 here]}

\section{CONCLUSIONS}

There is a consensus among macroeconomists that output fluctuations are very persistent and that long-term growth is not as stable as a deterministic trend would suggest. Empirical estimates of persistence display, however, large and significant differences across countries. We have shown that these differences can be almost fully explained by differences in long-term growth rates. Countries that grow faster have more persistent business cycles. In general, current business cycle models do not predict any correlation between these two variables as they treat one of the two, long-term growth rates, as an exogenous variable. For example, if all countries followed a random walk with a drift, then the degree of persistence would be the same in all countries even if the size of the drift varied.

We have looked at the concept of persistence within the context of an endogenous growth model and showed that, in this setting, transitory disturbances become persistent as they have effects in the amount of resources allocated to

\footnotetext{
22 See Bruno (1993) and Pindyck and Solimano (1993) for evidence on the effects of volatility on investment and growth.

23 A regression produces a coefficient of 0.06 with standard deviation equal to 0.18 .
} 
growth. Furthermore, the observed positive correlation of persistence and growth is a natural outcome in these models.

Our results suggest that stochastic growth is necessary to understand important features of the transmission of business cycles. But stochastic growth cannot be simply reduced to the presence of exogenous permanent shifts in the production function, as it is usually assumed in RBC models, the cyclical behavior of the resources allocated to growth needs to be taken into account. Indeed, if our goal is to analyze features of the business cycle such as persistence, the use of models where fluctuations are deviations around a steady-state solution to a neoclassical (Solow-type) growth model can be misleading.

Understanding all the implications that the endogeneity of growth has for business cycles is an open area for future research. One could imagine that, in these models, the transmission of shocks can lead to economic fluctuations that are quite different from the ones generated by a model where growth is treated as exogenous. The dynamics are possibly richer and could account for some of the empirical observations that are currently unexplained by business cycle models. ${ }^{24}$

24 For example, Rotemberg and Woodford (1996) show that the standard RBC model is unable to explain the actual size of forecastable movements in output. The only solution to this puzzle is to have transitory shocks having very persistent effects on output. Allowing for growth dynamics to have a role in these models, as in Section 4, might be able to address some of their limitations. 


\section{APPENDIX}

Parameters in the linearization

The linearization of Section 4.2 leads to the following parameters used in the paper

$$
\begin{gathered}
\kappa_{1}=\frac{A+(1-\delta)}{\left(1-S^{*}\right)} \gamma\left(1-\delta+S^{*} A\right)^{\gamma-1} \\
\kappa_{2}=-(1-\delta) \gamma\left(1-\delta+S^{*} A\right)^{\gamma-1} \\
\kappa_{3}=\beta \gamma \frac{A+(1-\delta)}{\left(1-S^{*}\right)} \\
\kappa_{4}=\beta[A(1-\gamma)-\gamma(1-\delta)]
\end{gathered}
$$

\section{Persistence and $\theta$}

Persistence can be calculated from expression (13)

$$
\Delta y_{t}=(1-(1-\theta) L) C(L) \epsilon_{t}
$$

Using the assumption that $\hat{z}$ follows an $A R(1)$ process, this equation can be rewritten as

$$
\Delta y_{t}=\left(1+(\rho-(1-\theta)) L+\left(\rho^{2}-(1-\theta) \rho\right) L^{2}+\left(\rho^{3}-(1-\theta) \rho^{2}\right) L^{3}+\ldots . .\right) \epsilon_{t}
$$

By adding up the coefficients from the lag polynomial we obtain

$$
P^{J}=\rho^{J}+\theta\left(1+\sum_{j=1}^{J-1} \rho^{j}\right)
$$

which is increasing in $\theta$ for any value of $J$. Long-run persistence is just

$$
P=\frac{\theta}{1-\rho}
$$

The second measure of persistence $V^{J}$ can be written as

$$
V=|P|^{2} \frac{\operatorname{var}(\epsilon)}{\operatorname{var}(\Delta y)}
$$

From (A.2), the variance of $\Delta y$ is equal to

$$
\operatorname{var}\left(\Delta y_{t}\right)=\left[1+(\rho-(1-\theta))^{2}+\rho^{2}(\rho-(1-\theta))^{2}+\rho^{4}(\rho-(1-\theta))^{2}+\ldots .\right] \sigma_{\epsilon}^{2}
$$

which can be simplified into

$$
\operatorname{var}\left(\Delta y_{t}\right)=\frac{2(\theta-1)(\rho-1)+\theta^{2}}{1-\rho^{2}} \sigma_{\epsilon}^{2}
$$


Using $(A .4),(A .5)$ and $(A .6)$,

$$
V=\frac{\theta^{2}\left(1-\rho^{2}\right)}{(1-\rho)^{2}\left(\theta^{2}+2(1-\rho)(1-\theta)\right)}
$$

This expression is increasing in $\theta$ as long as $\theta<2$, which will be satisfied as long as $\Delta y$ is a stationary series (as long as $y$ is an $\mathrm{I}(1)$ process). 


\section{REFERENCES}

Aghion, Philippe and Peter Howitt (1998). Endogenous Growth Theory. MIT Press, Cambridge.

Blanchard, Olivier and Danny Quah (1989). "The Dynamic Effects of Aggregate Supply Demand Disturbances." American Economic Review, 79.

Bruno, Michael (1993). Crisis, stabilization, and economic reform: Therapy by consensus. Clarendon Lectures in Economics. Oxford; New York; Toronto and Melbourne: Oxford University Press, Clarendon Press.

Caballero, Ricardo and M.Hammour (1994). "The Cleansing Effects of Recessions." American Economic Review. 84.

Campbell, John Y. and N. Gregory Mankiw (1989). "International Evidence on the Persistence of Economic Fluctuations." Journal of Monetary Economics, 23 .

Campbell, John Y. and N. Gregory Mankiw (1987). "Permanent and Transitory Components in Macroeconomic Fluctuations." American Economic Review Proceedings.

Cochrane, John H. (1988). "How Big is the Random Walk in GNP." Journal of Political Economy, 96, 5 .

Cochrane, John H. (1992) "Permanent and Transitory Components of GNP and Stock Prices." Quarterly Journal of Economics, 109(1).

Cogley, Timothy (1990). "International Evidence on the Size of the Random Walk in Output." Journal of Political Economy, 98(3).

Fatás, Antonio (1994). "Do Business Cycles Cast Long Shadows: Short-Run Persistence and Economic Growth." INSEAD Working Paper, 94/51.

Gali, Jordi and M. Hammour (1991). "Long-run Effects of Business Cycles." University of Columbia Mimeo.

Hall, Robert (1991). "Recessions as Reorganizations". NBER Macroeconomics Annual.

King, Robert G., Charles I. Plosser and Sergio T. Rebelo (1988). "Production, Growth and Business Cycles, II. New Directions." Journal of Monetary Economics. 21.

King, Robert G., Charles I. Plosser, James H. Stock and Mark W. Watson (1991). "Stochastic Trends and Economic Fluctuations." American Economic Review. 81(4). 
Kydland, Finn. E. and Edward C. Prescott (1982). "Time to Build and Aggregate Fluctuations." Econometrica. 50, 6.

Nelson, Charles and Charles Plosser (1982). "Trends and Random Walks in Macroeconomic Time Series." Journal of Monetary Economics 10.

Pindyck, Robert S. and Andres Solimano (1993). "Economic Instability and Aggregate Investment." NBER macroeconomics annual.

Romer, Paul M. (1989). "Crazy Explanations for the Productivity Slowdown." NBER Macroeconomics Annual.

Rotemberg, Julio and Michael Woodford (1996). "Real Business Cycle Models and the Forecastable Movements in Output, Hours, and Consumption." American Economic Review. 86(1).

Shapiro, Matthew and Mark Watson. (1988) "Sources of Business Cycle Fluctuations." NBER Macroeconomics Annual.

Stadler, George W. (1986). "Real Versus Monetary business cycle theory and the statistical characteristics of output fluctuations." Economic Letters. 22.

(1990). "Business Cycles Models with Endogenous Technology." American Economic Review. 4, Sept.

Summers, Robert and Alan Heston. (1991). "The Penn World Table (Mark 5): An Expanded Set of International Comparisons, 1950- 1988." Quarterly Journal of Economics. 106, 2. 
Figure 1. Persistence and Growth. G-7 Countries

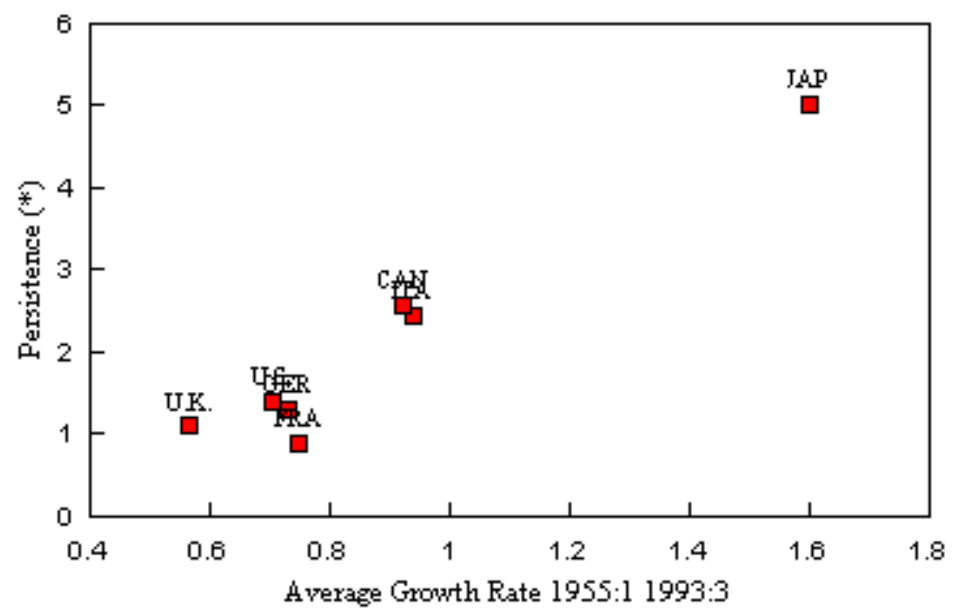

(c) Variance ratio, windoun=20 quarters

Source: International Financial Statistics, IMF

Figure 2. Persistence and Growth. Quarterly Data

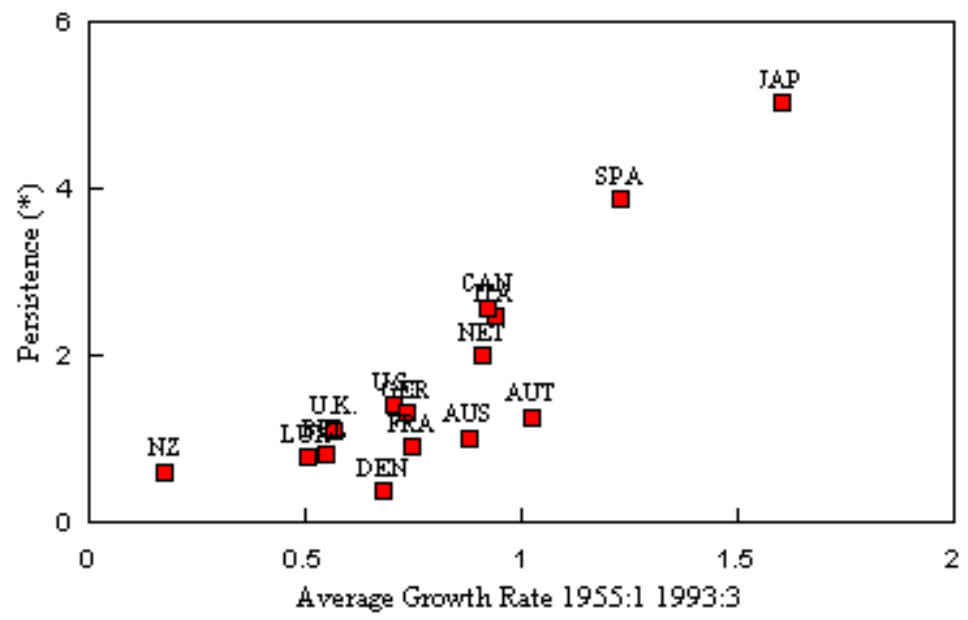

(8) Variance ratio, windom $=20$ quarters

Source: International Financial Statistics, IMF 
Figure 3. Persistence and Growth. Annual Data

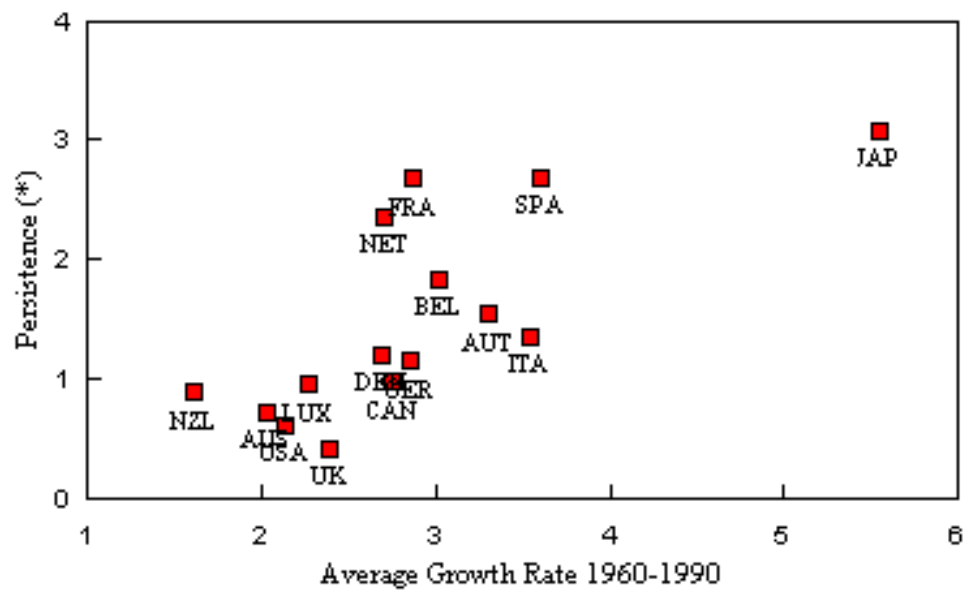

(*) Variance ratio, windoun=5 years

Source: SummersHeston (1991)

Figure 4. Impulse-Response Function

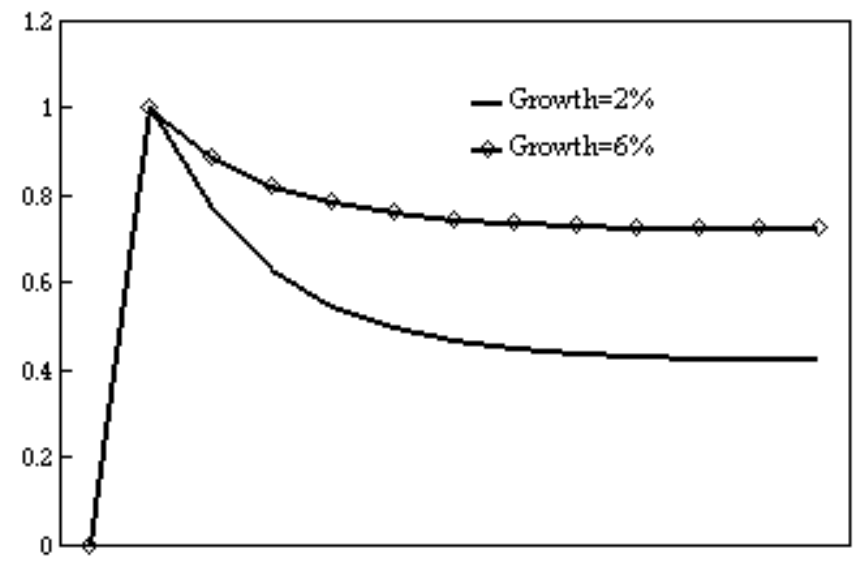


Figure 5. Cyclical and Permanent Components

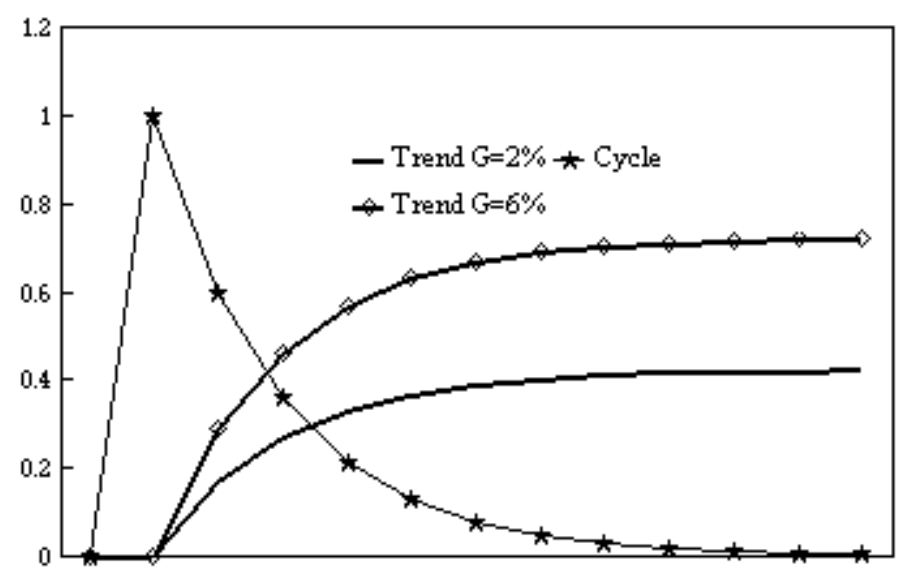

Figure 6. Volatility and Growth

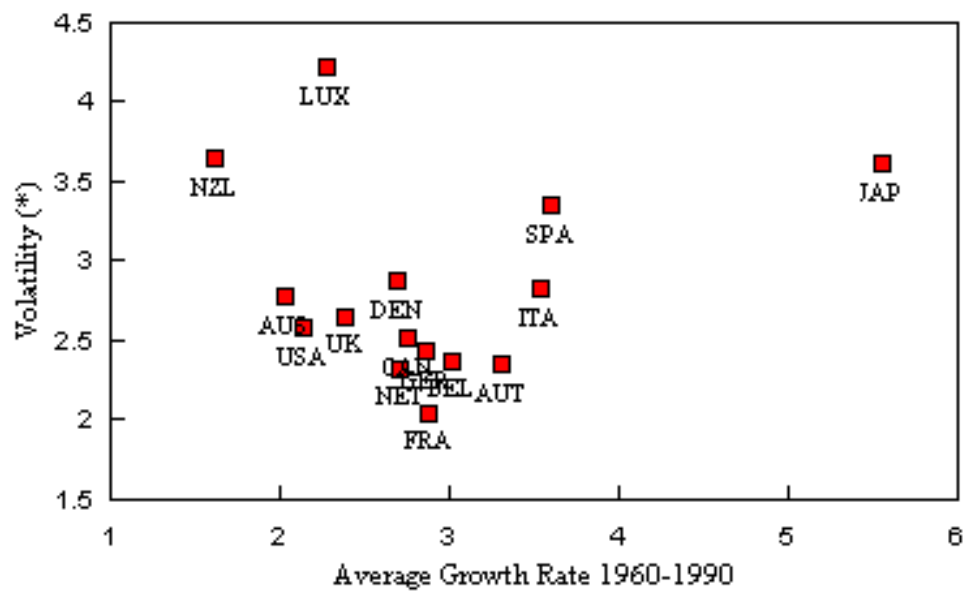

(c) Standard Deviation Dutput Grounth Source: SummersHeston (1991) 